\title{
Characterization of the high-temperature behavior of PBF-EB/M manufactured $\gamma$ titanium aluminides
}

\author{
M. Teschke ${ }^{1} \mathbb{D} \cdot$ J. Moritz $^{2,3} \cdot$ L. Telgheder $^{1} \cdot$ A. Marquardt $^{2,3} \cdot$ C. Leyens $^{2,3} \cdot$ F. Walther $^{1}$ (D)
}

Received: 20 August 2021 / Accepted: 31 January 2022 / Published online: 24 February 2022

(c) The Author(s) 2022

\begin{abstract}
Due to their high specific strength and temperature resistance, $\gamma$-titanium aluminides ( $\gamma$-TiAl) have a growing importance for automotive and aerospace applications. However, conventional processing is very challenging due to the inherent brittleness of the material. Therefore, new manufacturing techniques and methods have to be established. Additive manufacturing techniques such as electron powder bed fusion (PBF-EB/M) are favored, since they enable near net shape manufacturing of highly complex geometries. The high preheating temperatures, which typically occur during PBF-EB/M, can significantly improve the processability of TiAl and facilitate the fabrication of complex parts. In this study, a previously optimized material condition of the $\beta$-solidifying TNM alloy TNM-B1 (Ti-43.5Al-4Nb-1Mo-0.1B) was manufactured by PBF-EB/M. The resulting microstructure, defect distribution and morphology, and mechanical properties were characterized by means of characterization methods, e.g., CT, SEM, light microscopy, hardness measurements, and tensile tests. A special focus was on the mechanical high-temperature behavior. The pronounced sensitivity of the material to defects and internal notches, e.g., due to lack of fusion defects (misconnections) which were found in the as-built condition, was identified as a main cause for premature failure below the yield point due to the low ductility. This failure was analyzed and potential improvements were identified.
\end{abstract}

Keywords Additive manufacturing $\cdot$ Electron powder bed fusion $\cdot$ PBF-EB titanium aluminides $\cdot$ Mechanical properties . Tensile test

\section{Introduction}

Titanium aluminides (TiAl) can be used at application temperatures of up to $750-850{ }^{\circ} \mathrm{C}$ due to their high specific strength and stiffness, oxidation resistance, and good creep properties [1-3]. These properties make them an attractive material for aerospace engineering as well as for automotive and power plant applications [4-6]. With a density of around $4 \mathrm{~g} / \mathrm{cm}^{3}$, they can replace the much heavier nickelbase superalloys (density about $8 \mathrm{~g} / \mathrm{cm}^{3}$ ) [7]. The first

M. Teschke

mirko.teschke@tu-dortmund.de

1 Department of Materials Test Engineering (WPT), TU

Dortmund University, Dortmund, Germany

2 Institute of Materials Science (IfWW), Technische Universität Dresden, Dresden, Germany

3 Department of Additive Manufacturing and Printing, Fraunhofer Institute for Material and Beam Technology IWS, Dresden, Germany commercial applications for $\gamma$-TiAl were low-pressure turbine blades, which were realized by General Electric Co. (GE) in 2006 [8]. However, TiAl exhibit a very brittle material behavior, i.e., low ductility and fracture toughness, at room temperature, making them very difficult to machine. Conventional manufacturing processes are isothermal forging or centrifugal casting, combined with post-treatments in the form of hot isostatic pressing (HIP) and heat treatment (HT) $[7,9]$. However, these are very resource-consuming and expensive. For this reason, additive manufacturing (AM) represents a promising alternative as a near net shape manufacturing process which offers significantly greater freedom of design [10].

There is a continuously growing research interest in $\mathrm{AM}$ technologies, with powder bed fusion (PBF) processes playing a major role. Among the different PBF techniques available, electron beam powder bed fusion (PBF-EB/M), also known as selective electron beam melting (sEBM), offers the most benefits in processing TiAl. Due to the high process temperatures of over $1000^{\circ} \mathrm{C}$, cracking of the parts can be prevented, as it 
can often be observed during other AM processes [11, 12]. Another benefit is that the processing under a vacuum atmosphere decreases the risk of oxygen ingress and oxidation [12, 13]. In PBF-EB/M, an electron beam is used to successively preheat the powder bed and melt the cross-sectional area of the part in each layer, followed by lowering the build platform and applying a new layer of powder [11].

The first generation of $\gamma$-TiAl alloys exhibited low ductility at room temperature. Therefore, in the second generation, the aluminum content was increased to 48 at.- $\%$, thus significantly improving room-temperature ductility $[14,15]$. A well-known representative of this generation is the alloy Ti-48Al-2Cr- $2 \mathrm{Nb}$ (Ti-48-2-2) with fracture elongations of up to $3 \%$ after heat treatment [7]. However, this generation of alloys can only be operated up to $700{ }^{\circ} \mathrm{C}[5]$. The third generation of $\gamma$-TiAl alloys contains $5-10$ at. $\% \mathrm{Nb}$ and small amounts of $\mathrm{B}$ and $\mathrm{C}$. The increased $\mathrm{Nb}$ content compared to previous $\gamma$-TiAl generations makes solidification through the $\beta$-phase-field easier [7, 16]. An important representative is the alloy TNM-B1 (Ti-43.5Al$4 \mathrm{Nb}-1 \mathrm{Mo}-0.1 \mathrm{~B})$. This alloy is optimized for the casting and forging process as segregation is reduced and the alloy has good hot workability $[7,16]$. A special property is that the TNM alloy solidifies via the body-centered cubic $\beta$-Ti(Al) phase and not, as it is usual for many TiAl alloys, peritectically [12]. The alloy can be used up to $750-800{ }^{\circ} \mathrm{C}$ and has been applied in a low-pressure turbine (LPT) blade into the geared turbofan (GTF) jet engine since 2016 [5, 17]. However, the ductility of this alloy is low. After heat treatment, a room-temperature ductility of $1.16 \%$ can be reached for cast components [18]. This alloy has been described in detail by Clemens et al. [19]. The latest TiAl generation is currently under development and characterization [20,21]. The focus is on increasing the ductility at room temperature and improving the high-temperature properties.

Various studies have been published on the manufacturing of various $\gamma$-TiAl alloys by PBF-EB/M. First studies were performed by Cormier et al. [22]. In addition, further investigations regarding alloy design and process parameters were performed on Ti-45Al-7Nb-0.3 W [23], Ti-47Al-2Cr-2Nb [24-26] and Ti-48Al-2Cr-2Nb [27-29] alloys. Aluminum evaporation during the PBF-EB/M process was frequently observed and resulted in an irregular microstructure distribution [26, 30, 31].

The processing of the alloy TNM-B1 via PBF-EB/MB was investigated by Wartbichler et al. [13] and Mayer et al. with a focus on the microstructure [12]. An inhomogeneous distribution of the aluminum content and the present phases as well as a pronounced solidification texture along the building direction were observed.

So far, there are only a few studies on the mechanical characterization of PBF-EB/M manufactured $\gamma$-TiAl [25, 29, 32]. The alloy TNM-B1 was mainly mechanically investigated in material states produced by other manufacturing processes (e.g., forging). Particularly noteworthy here are the results of Mayer et al. [12] and Schwaighofer et al. [18]. To date, there are no published studies on the complete mechanical characterization of the PBF-EB/M-processed alloy TNM-B1.

This paper is therefore intended to contribute to the complete characterization of the alloy TNM-B1 manufactured by PBF-EB/M. For this purpose, an as-built condition of the alloy TNM-B1 was investigated, which was identified in the previous investigations as optimal concerning porosity, surface roughness, and evaporation of aluminum [33]. Therefore, specimens were produced with this parameter set, and the as-built state was characterized by various destructive and non-destructive testing methods. The mechanical strength was evaluated by means of tensile tests at room temperature and elevated, application-relevant test temperatures. Subsequently, the results are evaluated with help of fracture surface examinations and compared with results from other publications. Furthermore, the results will be used to optimize the manufacturing process and identify suitable post-treatments.

\section{Materials and methods}

\subsection{Materials}

For PBF-EB/M, spherical gas atomized powder was obtained from GfE Metalle und Materialien (Nuremberg, Germany). The powder had the chemical composition Ti43.5 Al-4Nb-1Mo-0.1B, with aluminum content increased by 3 at.-\% compared to conventional TNM-B1 ingots (third-generation $\gamma$-TiAl). Therefore, the alloy will be further defined as TNM-B1-mod. This was to compensate for the evaporation of aluminum in the manufacturing process. The chemical composition of the powder after atomization, determined by ICP-OES, is shown in Table 1 . The powder has a particle-size distribution between 60 and $145 \mu \mathrm{m}\left(D_{50}\right.$ of $83.6 \mu \mathrm{m})$.

All specimens were manufactured on the Arcam A2X machine (ARCAM AB, Mölndal, Sweden) and EBM Control
Table 1 Chemical composition (ICP-OES)

\begin{tabular}{llllllll}
\hline Element & $\mathrm{Ti}$ & $\mathrm{Al}$ & $\mathrm{Nb}$ & $\mathrm{Mo}$ & $\mathrm{B}$ & $\mathrm{Si}$ & $\mathrm{Fe}$ \\
\hline at.-\% & 50.0 & 44.7 & 4.08 & 1.00 & 0.121 & 0.129 & 0.003 \\
wt.-\% & 58.6 & 29.5 & 9.28 & 2.34 & 0.032 & 0.089 & 0.004 \\
\hline
\end{tabular}


3.2 software with the manufacturing parameters given in Table 2. The parameters were identified as optimal parameters with respect to achievable relative density and top surface quality in the previous studies [33]. A central composite design was used to determine the influence of beam current, scan speed, line offset, focus offset, and layer thickness on the resulting part density. Using the optimized parameter set for PBF-EB/M, the resulting aluminum content after the process amounted to $43.7 \pm 0.6$ at.- $\%$, which is in good agreement with the chemical composition of conventionally processed TNM-B1. The aluminum content was measured via energydispersive X-ray spectroscopy (EDX).

For the build jobs, a $150 \mathrm{~mm} \times 150 \mathrm{~mm}$ start plate was used, which was preheated to $1020^{\circ} \mathrm{C}$. The preheating parameters, which are applied before and after the actual melting step in each layer to sinter the particles in the powder bed, were adjusted to maintain these temperatures in the process zone throughout the build process. The process was carried out under a controlled vacuum of approximately $10^{-3} \mathrm{mbar}$. For each build job, 36 cylinders with a diameter of $20 \mathrm{~mm}$ and a height of $67 \mathrm{~mm}$ were manufactured parallel to the building direction (vertical, $x z$-plane). The specimens were not subsequently heat-treated or hot isostatically pressed. All investigations were carried out in the as-built condition.

The specimens were subsequently machined by milling them into the specimen geometry shown in Fig. 1. The specimen geometry is partly based on DIN EN 6072. The specimen diameter in the test area is $5.64 \mathrm{~mm}$, resulting in a crosssectional area of $25 \mathrm{~mm}^{2}$. The surface quality was further improved by manual grinding and polishing. The specimen geometry was designed to be used for future planned fatigue tests to ensure consistency of results.

Table 2 Process parameters for PBF-EB/M [33]

\begin{tabular}{lllll}
\hline Beam current & Scan speed & Focus offset & Line offset & $\begin{array}{l}\text { Layer } \\
\text { thickness }\end{array}$ \\
\hline $15 \mathrm{~mA}$ & $4000 \mathrm{~mm} / \mathrm{s}$ & $3 \mathrm{~mA}$ & $0.1 \mathrm{~mm}$ & $70 \mu \mathrm{m}$ \\
\hline
\end{tabular}

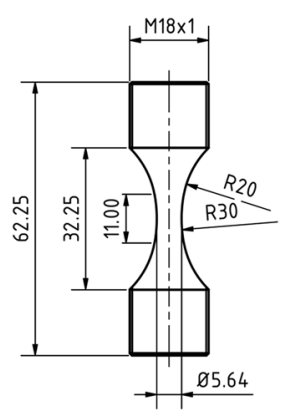

Fig. 1 Specimen geometry for tensile tests

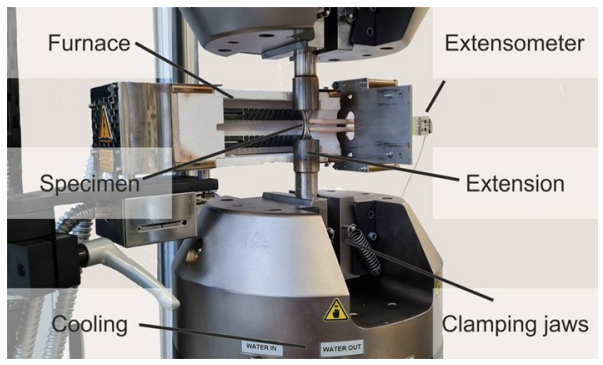

Fig. 2 Test setup for quasi-static tensile tests at high temperature

\subsection{Methods}

The test setup for the tensile tests can be seen in Fig. 2 . The tests are performed on an Instron 8802 servohydraulic fatigue testing system (Instron, Norwood, USA). An Instron CP100635 high-temperature furnace is used and the strain is detected with a high-temperature extensometer Sandner EXH 10-1A (Sandner Messtechnik, Biebesheim, Germany), which has a measuring length of $10 \mathrm{~mm}$. The hydraulic chucks were water-cooled to prevent overheating. Since the specimen length was not long enough due to the height of the furnace, the specimens were extended using a self-developed thread adapter made of Inconel $602 \mathrm{CA}$.

The tensile tests were carried out at room temperature $\left(\mathrm{RT}=20^{\circ} \mathrm{C}\right)$ and different high temperatures $(400,700,750$, 800 , and $850^{\circ} \mathrm{C}$ ) according to DIN EN ISO 6892-1 and 2. After reaching the test temperature, it was held for approx. $10 \mathrm{~min}$ and the test was then performed stress-controlled with the estimated strain rate of $\dot{\varepsilon}_{\mathrm{L}_{\mathrm{e}}}=2,5 \cdot 10^{-4} \mathrm{~s}^{-1}$. At least three tests were performed for each test temperature.

For the microstructural characterization of the initial state as well as selected mechanically tested specimens, metallographic sections, which are extracted parallel to the building direction (xz-plane), were prepared. For this purpose, the specimens were embedded, ground with $\mathrm{SiC}$ paper (\#500 to \#2000), and subsequently polished with a diamond suspension (grain size: $0.01 \mu \mathrm{m}$ ). Microscopic investigations were performed on the light microscope Axio Imager M1 (Carl Zeiss, Goettingen, Germany) as well as on the scanning electron microscope (SEM) Mira 3 XMU (Tescan, Brno, Czech Republic). In addition, fracture surfaces of selected specimens were observed with SEM. In the previous investigations, the initial condition was already characterized using EBSD scans. The exact method can be found in [33].

Concerning the initial hardness, macro-hardness measurements were carried out on a Wolpert Dia-Testor 2Rc Vickers hardness-testing machine (Instron, Norwood, MA, USA) with a static load of $294.2 \mathrm{~N}$ (HV30). The indentations were conducted along building direction at a distance of $1.8 \mathrm{~mm}$.

To characterize the defect state, the $\mu$-computed tomography ( $\mu$-CT) Nikon XT-H 160 system (Nikon Metrology, 
Tokyo, Japan) with an acceleration voltage of $160 \mathrm{kV}$ was used. The scan parameters can be found in Table 3. The $\mu$-CT scans were analyzed using VGStudio Max 2.2 software (Volume Graphics, Heidelberg, Germany). A detailed description of the methodology can be found in [34]. To describe the 3D pore morphology, the sphericity $S$ is used (see Eq. 1), which is influenced by the defect volume $V$ and the pore surface $A$ [35]. $S$ is defined between 0 and 1 , where 1 describes the ideal spherical shape

$S=\frac{\pi^{1 / 3}(6 V)^{2 / 3}}{A}$.

\section{Results and discussion}

\subsection{Characterization of the initial state}

Figure 3 shows the HV30 hardness values determined on an exemplary specimen in the $z$-direction (parallel to the building direction). The average HV30 hardness value is $414 \pm 5$. The HV30 hardness values varied over the building direction in a scatter band between 413 and 426 HV 10, whereby no dependence of the hardness along the build direction can be recognized. Therefore, the process parameters enabled a constant hardness and thus microstructure across the building direction.

To characterize the defect state, pore analyses were performed on three specimens. Figure 4 shows an example of a pore analysis to characterize the location, number, and shape of the pores. A total volume of all three specimens of 261 $\mathrm{mm}^{3}$ was analyzed and the relative density was calculated to be $99.88 \%$. In comparison to the previously conducted study regarding process parameter optimization, where relative densities of $99.9 \%$ could be achieved using the exact same parameter, this value is considerably lower [33]. This indicates that scaling the specimen volume without adjusting the parameters may result in slightly increased density. As shown in Fig. 4a, the pores are randomly distributed within the volume. However, based on the reconstructed 3D volume, it cannot be determined if pores are preferably located inside grains or at grain boundaries. Figure $4 \mathrm{~b}$ shows the equivalent pore diameter $d_{p}$ versus defects per $\mathrm{mm}^{3}$ (defect density). The pores follow a classical normal distribution, with most pores having an equivalent pore diameter of 50-110 $\mu \mathrm{m}$. Pores $<30 \mu \mathrm{m}$ cannot be detected by this method. Figure $4 \mathrm{c}$ shows the sphericity $S$ versus the equivalent pore diameter $d_{p}$. Most pores have a sphericity $S<0.5$, and some pores have a sphericity $S<0.3$. The pores, therefore, have a very flat shape.

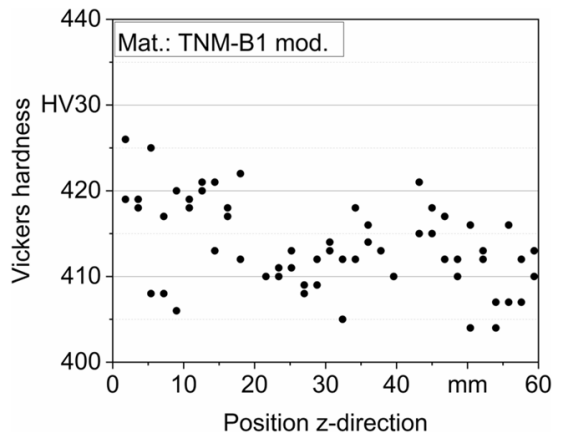

Fig. 3 Hardness profile of $\gamma$-TiAl along building direction

Figure 5 shows a light microscope image of a polished specimen. In contrast to the specimens examined in the CT, a specimen with a diameter of $20 \mathrm{~mm}$, as manufactured in the build job, is shown. In the image, which was created parallel to the building direction ( $x z$-plane), very flat defects, as well as round defects, can be identified. Cracks are not detectable. The flat defects are misconnections, which can be described by an elongated shape with sharp edges. They occur between melting layers due to a lack of fusion (LOF). Again, these findings are in contrast to [33], where LOF defects could fully be avoided using the optimized parameter set. A possible explanation might be that the parameter set was optimized using cubic specimens with an edge length of $10 \mathrm{~mm}$. For the cylindrical specimens manufactured in this study, there is a variation in the length of the scan vector due to the different cross-sectional area. Consequently, while the volumetric energy density remained constant, the mean beam return time was altered, leading to inconsistent melting conditions which might have resulted in the observed LOF defects [21,33]. Algorithms for dynamic process parameter adjustment have been developed by the machine manufacturer and are implemented in the control software to compensate for this effect and ensure constant melting conditions even for complex components. However, since these algorithms are not accessible to the machine user, it is not possible to draw conclusions about the influence of individual process parameters when the automatic mode is used. For this reason, in this study, the process parameters for the PBF-EB/M process were manually set to constant values according to Table 2. Some sources describe that the LOF can be minimized by increasing the energy input during melting [27, 36, 37]. However, it should be kept in mind that higher energy inputs might be associated with growing aluminum evaporation, inhomogeneous microstructures, and an increased risk of swelling [33]. As can be seen in Fig. 5, the LOF are
Table 3 Scanning parameters for the computed tomography scans $(\mu-\mathrm{CT})$

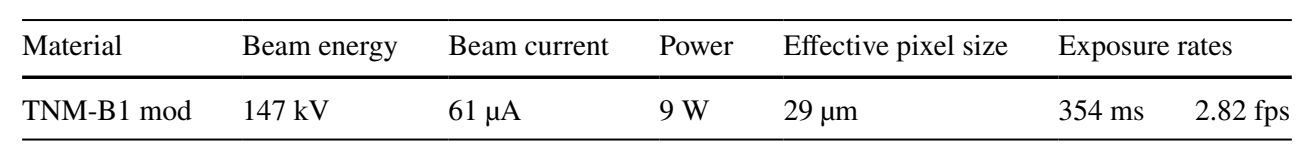


(a) Defect volume

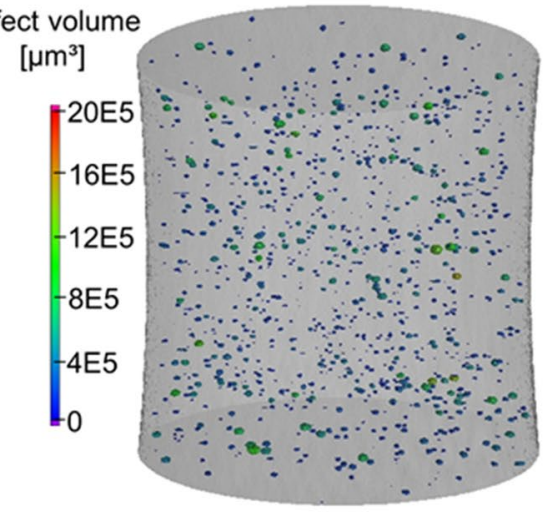

(b)

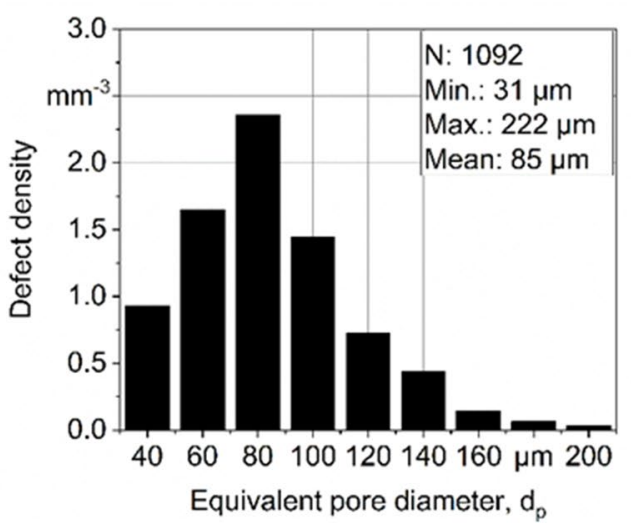

(c)

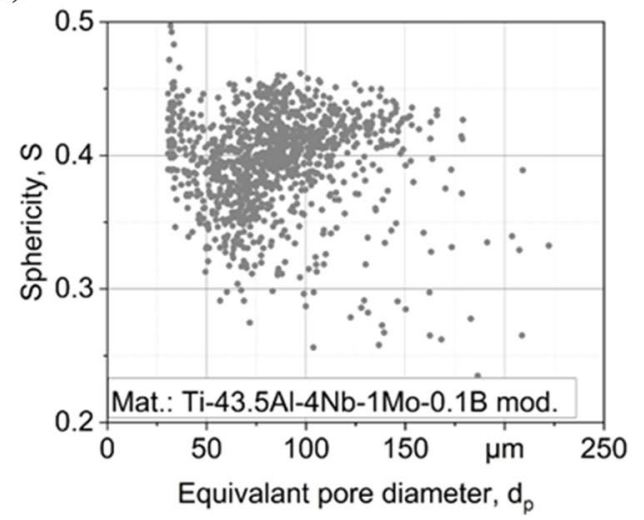

Fig. 4 3D pore analysis and defect state of $\gamma$-TiAl: a location of pores; $\mathbf{b}$ number of pores; $\mathbf{c}$ sphericity

Fig. 5 Light microscope image in $x z$-plane (parallel to the building direction) in as-built state

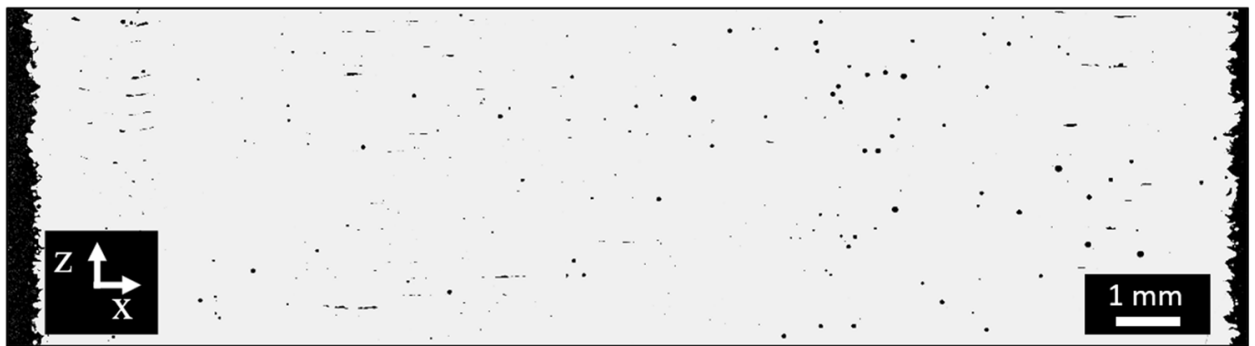

arranged orthogonally to the building direction and occur predominantly in the edge region of the specimen. However, they can also be observed in the test area of the tensile specimens, i.e., in the center of the specimen. The spherical defects can be classified as gas pores. They form when residual gas, which originates from hollow powder particles or interstices in the powder bed, becomes entrapped in the material due to the rapid solidification of the melt $[38,39]$. In this way, gas pores can form despite the process vacuum. Both types of defects can significantly impact the mechanical properties, with LOF defects being most critical due to the low fracture toughness of $\gamma$-TiAl [40, 41]. Hence, the defects may outweigh the influence of the microstructure [42]. The arrangement of the defects orthogonally to the building direction is particularly critical, since the LOF defects act like internal notches. The specimens were tested in the as-built condition, without HIP or HT. Nevertheless, the influence of HIP and HT will be addressed in detail in future investigations. Preliminary results proved that an HIP treatment at $1200{ }^{\circ} \mathrm{C}$ for $4 \mathrm{~h}$ at $200 \mathrm{MPa}$ could successfully reduce the amount of both LOF and gas porosity to a minimum, as shown in Fig. 6.

Figure 7 shows the microstructure in the initial state. The largest areas are occupied by the $\alpha_{2}-/ \gamma$-colonies, which can be recognized by the lamellar structure (white lamellae). The $\gamma$-phase appears in the form of globular grains, which appear in dark gray. The light areas can be ascribed to the 


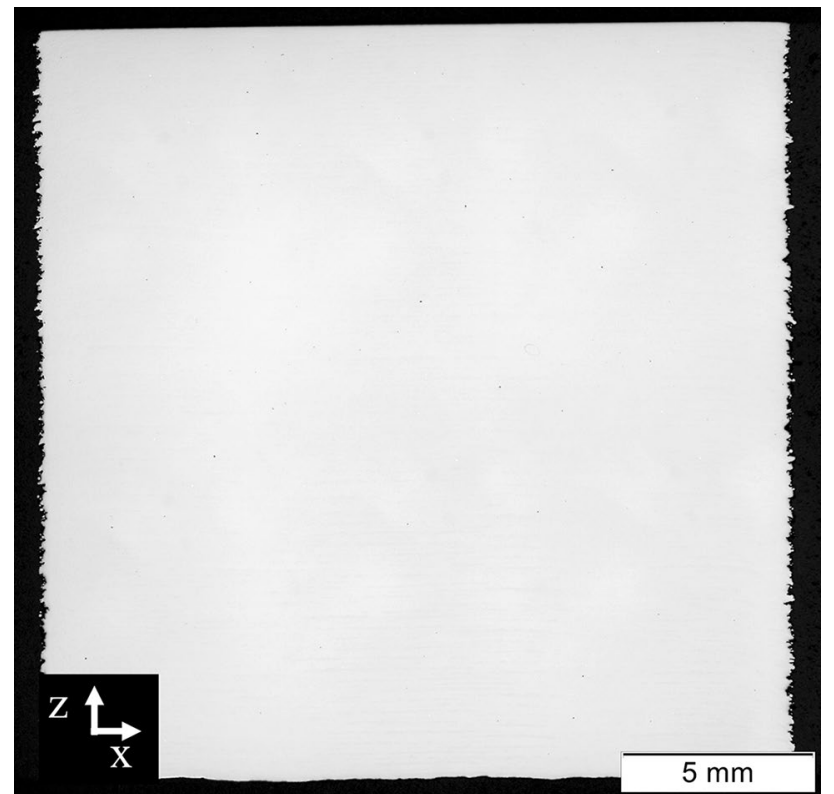

Fig. 6 Light microscope image in $x z$-plane (parallel to the building direction) after hot isostatic pressing (HIP)

$\beta_{\mathrm{O}}$-phase [13], which is localized at the grain boundaries. In previous investigations, the condition has already been studied with the help of EBSD scans [33]. It was found that the phase fraction of $\gamma$-phase is over $90 \%$ compared to $\beta$ - and $\alpha_{2}$-phase. The grain size was found to be less than $4 \mu \mathrm{m}$ with standard size distribution.

\subsection{Tensile tests}

Figure 8 shows the ultimate tensile strength (UTS), Young's modulus (YM), and total strain (TS) values determined in the quasi-static tensile test graphically, considering the standard deviation. The values were averaged over at least three tests. Since the tests all failed below the yield point, the total strain is completely elastic (see Fig. 9). The corresponding absolute values are listed in Table 4.

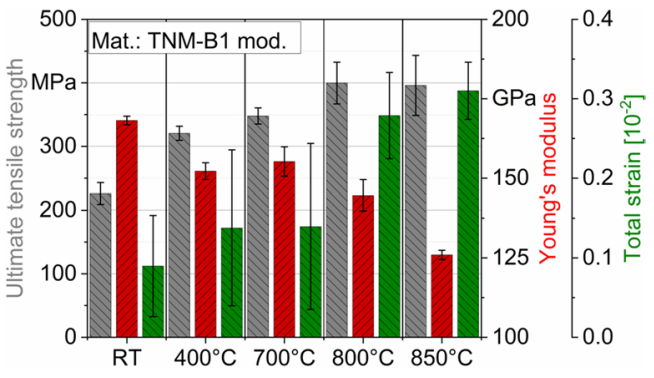

Fig. 8 Ultimate tensile strength, Young's modulus, and total strain in tensile tests at RT, $400{ }^{\circ} \mathrm{C}, 700{ }^{\circ} \mathrm{C}, 800{ }^{\circ} \mathrm{C}$, and $850{ }^{\circ} \mathrm{C}$

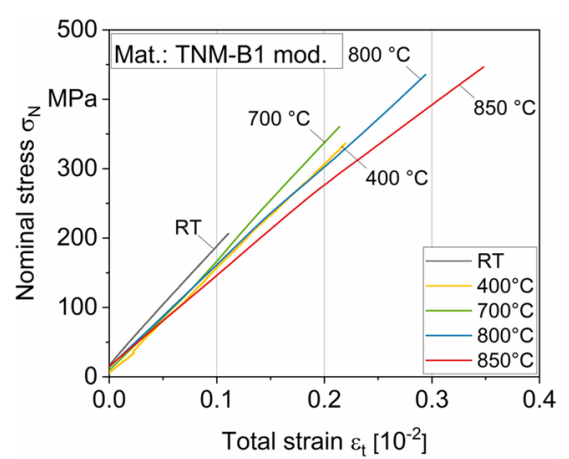

Fig. 9 Nominal stress-total strain relationship for one exemplary test each at RT, $400{ }^{\circ} \mathrm{C}, 700{ }^{\circ} \mathrm{C}, 800{ }^{\circ} \mathrm{C}$, and $850{ }^{\circ} \mathrm{C}$

The UTS for RT is $226 \mathrm{MPa}$ and increases with increasing test temperature. At $400{ }^{\circ} \mathrm{C}$, it is increased by $42 \%$, at $850{ }^{\circ} \mathrm{C}$ by $75 \%$ compared to the tests at RT. The YM, on the other hand, decreases with increasing temperature. There is no significant difference between the test at $400{ }^{\circ} \mathrm{C}$ and $700{ }^{\circ} \mathrm{C}$. The $\mathrm{YM}$ at $\mathrm{RT}$ is $168 \mathrm{MPa}$, whereas at $850{ }^{\circ} \mathrm{C}$, it drops by $25 \%$ to $126 \mathrm{MPa}$. The total strain increases with the test temperature. At RT $\left(20^{\circ} \mathrm{C}\right)$ it is $0.09 \%$ and increases by $244 \%$ to $0.310 \%$ at $850{ }^{\circ} \mathrm{C}$. The TS values for $400{ }^{\circ} \mathrm{C}$ and $700{ }^{\circ} \mathrm{C}$ are comparable. However, due to the high standard deviation, this relationship is not significant. Figure 10 shows the fracture surfaces of a specimen tested at RT (a)
Fig. 7 SEM image in xz-plane (parallel to the building direction) (SE-Detector)
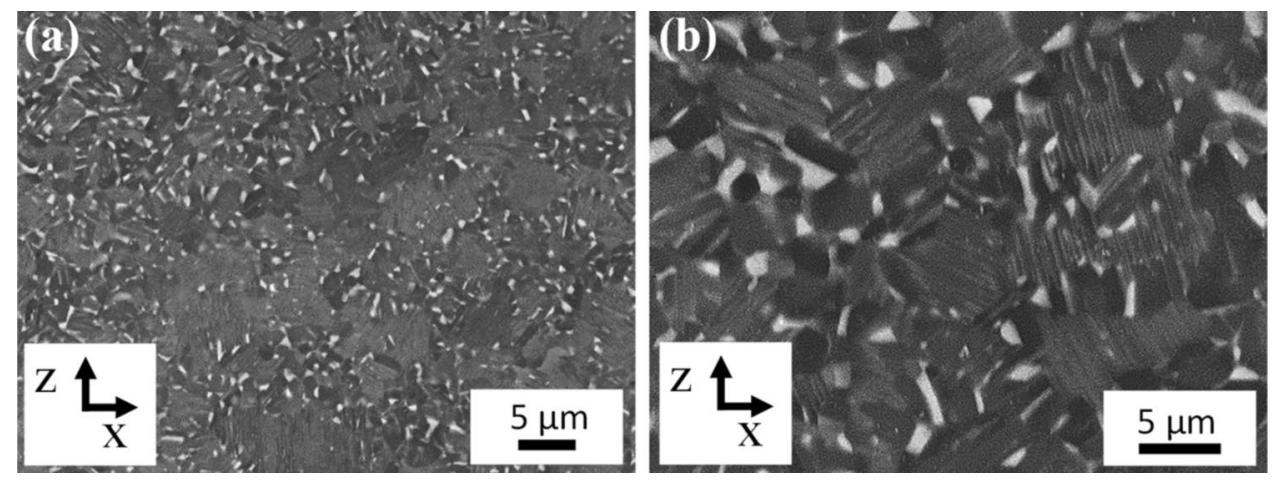
Table 4 Tabular listing of ultimate tensile strength (UTS), Young's modulus (YM), and total strain (TS)

\begin{tabular}{llll}
\hline Temperature & UTS $(\mathrm{MPa})$ & YM $(\mathrm{GPa})$ & TS $\left(10^{-2}\right)$ \\
\hline $\mathrm{RT}\left(20{ }^{\circ} \mathrm{C}\right)$ & $226 \pm 17$ & $168 \pm 1$ & $0.090 \pm 0.064$ \\
$400{ }^{\circ} \mathrm{C}$ & $321 \pm 11$ & $152 \pm 3$ & $0.138 \pm 0.098$ \\
$700{ }^{\circ} \mathrm{C}$ & $347 \pm 13$ & $155 \pm 5$ & $0.140 \pm 0.104$ \\
$800{ }^{\circ} \mathrm{C}$ & $400 \pm 33$ & $145 \pm 5$ & $0.279 \pm 0.054$ \\
$850{ }^{\circ} \mathrm{C}$ & $396 \pm 47$ & $126 \pm 1$ & $0.310 \pm 0.036$ \\
\hline
\end{tabular}

and a specimen that failed at $850{ }^{\circ} \mathrm{C}(\mathrm{b})$. In all tested cases, a lack of fusion (LOF) defect could be identified as a fracture initiator. The defect could consist of several pores, which were directly adjacent to each other, or one large pore. Pores close to the surface were particularly critical. Due to the high notch effect of the pores, a local stress concentration occurred, which led to the fracture of the specimen. The brittle material behavior makes the material particularly sensitive to this form of failure. Due to this behavior, the specimen failed even before reaching the yield point. Figure 11 shows the cross-section of the fracture surface of a specimen tested at $850{ }^{\circ} \mathrm{C}$. It can be observed clearly that the fracture behavior is intercrystalline. This can be applied to all specimens tested, independent of the test temperature.

The mechanical properties determined differ in part from those given in other sources. Significantly higher UTS of 556-700 MPa were obtained for other $\gamma$-TiAl manufactured with PBF-EB/M [25, 29, 32]. For the alloy TNM-B1, higher ultimate tensile strengths of $\sim 770-950 \mathrm{MPa}$ were also obtained but only in post-treated conditions (HIP and HT) and other manufacturing techniques $[12,18]$. Furthermore, in the literature, there is a decrease in UTS with increasing temperature $[12,18]$. In these investigation, the opposite was observed. The reason for this presumably are the previously described LOF defects (misconnections), and the resulting notch effect in combination with the brittle material behavior. This leads to premature failure due to local stress concentration at these defects. The influence of the defects outweighs the influence of the microstructure. This behavior was also described by Bruno et al. on Ti-6Al-4V manufactured by PBF-EB/M [42]. Ductility increases with increasing test temperature, which can be seen from the increasing total strain. As a result, the tolerance for local defects improves, and the UTS enlarges. However, as shown in Fig. 9, the total strain is in the elastic range until failure. At all test temperatures the specimens fail below the yield point.

The Young's modulus for the alloy TNM-B1 mod. manufactured by PBF-EB/M behaves similarly to that determined in the literature for cast TNM-B1. At RT, it is also $160 \mathrm{MPa}$ and drops significantly with increasing temperature [18]. However, the drop in PBF-EB/M manufactured TNM-B1 alloy for $800{ }^{\circ} \mathrm{C}$ is $30 \%$ less than cast and HIP TNM-B1. At the test temperatures of $400{ }^{\circ} \mathrm{C}$ and $700{ }^{\circ} \mathrm{C}$, no drop in the YM can be observed. Further investigations at this test temperature are necessary to clarify the relationship.

In these investigations, the high notch sensitivity of the PBF-EB/M manufactured TNM-B1 mod. was demonstrated. As a result, stress concentration occurs at the defects. Therefore, failure occurred before reaching the yield strength and the real UTS. However, the potential of the material becomes clear based on characteristic values determined on cast and post-treated TNM-B1 [12, 18], but also on characteristic values of the fourth generation of $\gamma$-TiAl [21]. Therefore, further adjustment of the process itself as well as the subsequent heat treatment will be addressed in future research activities. So far, the process has been optimized regarding porosity, surface roughness, and evaporation of aluminum [33]. However, it has become evident that a transfer of the optimized parameter sets identified in [33] to other geometries and part cross-sections is not straightforward. This is particularly important for the fabrication of complex components with cross-sectional areas that vary over the build height. A main function of the heat treatment will be to improve ductility and notch sensitivity. The characteristic values determined in this work shall serve as a benchmark for these future modifications. There are different approaches to optimize the mechanical properties, which should be considered in parallel:

- Reduction of defects by modifying the process parameters: Various sources suggest that LOF (misconnections) could be minimized by increasing the energy input during the melting step in the PBF-EB/M process $[27,36$, 37]. However, energy input that is too high leads to the opposite effect [43]. Furthermore, excessive energy input may lead to swelling and growing aluminum loss due to evaporation. High relative densities of $99.9 \%$ could be achieved by Moritz et al. [33] for a constant scan vector length using the parameters specified in Table 2. The occurrence of LOF defects in the specimens in this study, which were fabricated using the exact same parameters as in [33], provides evidence that a localized, dynamic adjustment of the process parameters to maintain consistent melt conditions might be crucial for manufacturing complex components with low residual porosity.

- Closing of pores by HIP: The pores identified as weak points (misconnections) can partially be closed by HIP [44]. This procedure is commonly used for TiAl alloys $[21,45,46]$. Typical application parameters for TNM-B1 are $1200{ }^{\circ} \mathrm{C} / 200 \mathrm{MPa} / 4 \mathrm{~h} /$ furnace cooling $[18,46]$. It could be shown that the majority of gas pores and LOF defects could be eliminated by HIP, which is promising for improving the mechanical properties. 
Fig. 10 Fractographic SEM images of fracture surfaces with close-up details: a tensile test at $\mathrm{RT}$; b tensile test at $850{ }^{\circ} \mathrm{C}$ (a)

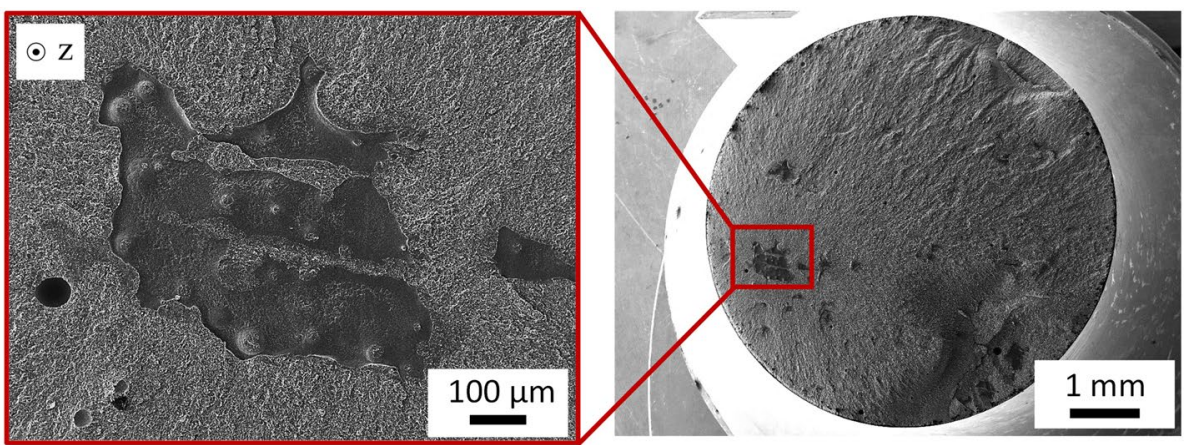

(b)

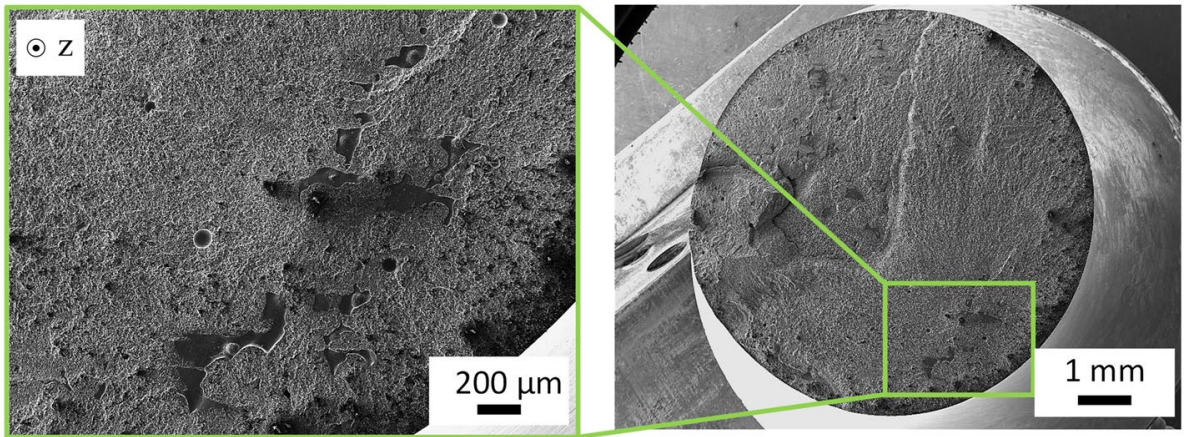

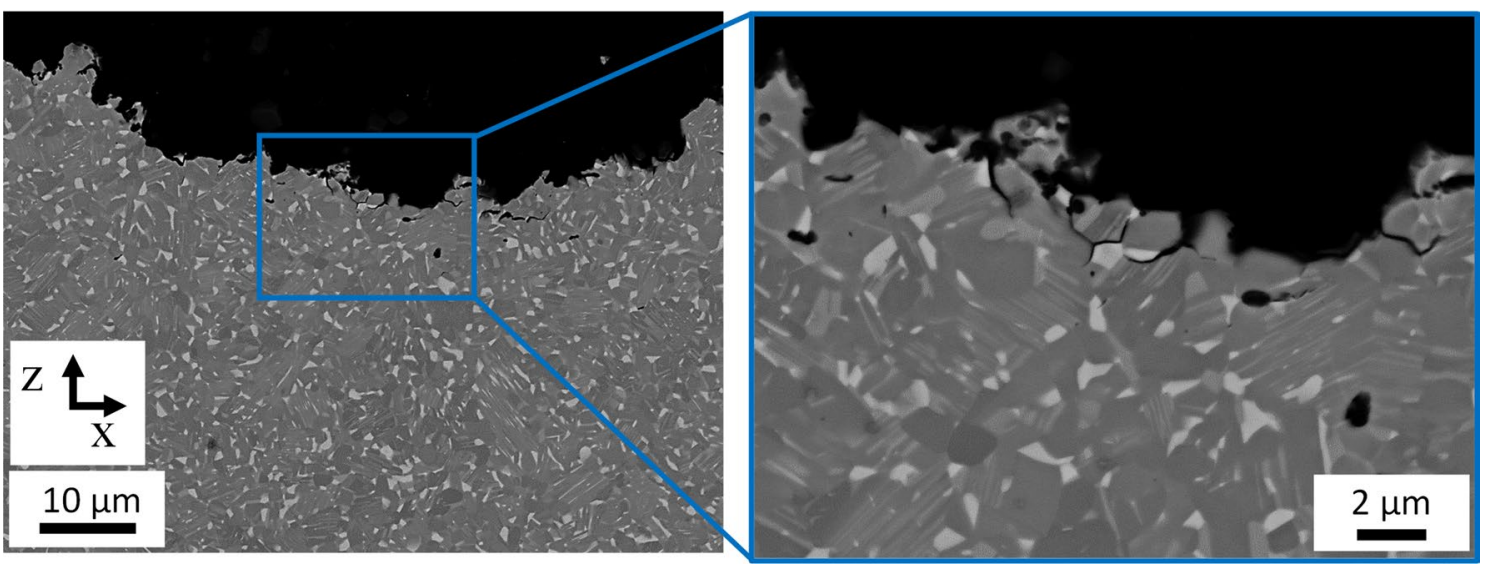

Fig. 11 Exemplary fracture propagation, shown based on an SEM image orthogonal to the fracture surface (BSE detector); specimen tested in tensile test at $850{ }^{\circ} \mathrm{C}$

- Increase of ductility by HT and thus increase of tolerance against defects: Various HT are known for TNM$\mathrm{B} 1$ in the as-cast condition $[12,18]$ as well as for other PBF-EB/M-manufactured TiAl alloys [21, 47]. The optimization of heat treatment strategies for achieving tailored microstructures with increased ductility will therefore be investigated.

- Since LOF defects are always orthogonal to the building direction, their orientation is known. By arranging the specimens parallel to the direction of the highest load, the ultimate tensile strength of the components and specimens can be increased despite LOF. The reason for this is the smaller cross-section area of the LOF due to the modified orientation, which can lead to a decrease in stress concentration. It is expected that this will result in significantly higher ultimate tensile strength.

\section{Conclusions and outlook}

Specimens of TNM-B1 alloy (Ti-43.5Al-4Nb-1Mo-0.1B) manufactured by electron powder bed fusion (PBF-EB/M) were investigated by means of various testing methods (CT, SEM, light microscope, hardness measurements, and tensile tests at elevated test temperatures). The specimens 
were manufactured parallel to the building direction (vertical) and then investigated in the as-built condition without post-treatment.

No significant variation of the hardness and thus the microstructure along the building direction could be detected. In addition, manufacturing-related defects are present in the form of gas pores and misconnections (lack of fusion defects orthogonal to the building direction). The ultimate tensile strength and total strain increase with increasing test temperature, reaching $400 \mathrm{MPa}$ and $0.3 \%$ at $800{ }^{\circ} \mathrm{C}$, respectively. Young's modulus decreases with the test temperature.

Due to the brittle material behavior, stress concentration occurred at the lack of fusion defects arranged orthogonally to the building direction, which is assumed to be the reason why all specimens failed there prematurely before reaching the yield point. The influence of the defects outweighs the influence of the microstructure. To improve the mechanical strength as well as the ductility, there are different approaches for future investigations:

- Reduction of defects by modifying the process parameters

- Closing of pores by hot isostatic pressing

- Increase of ductility by heat treatment

- Arranging the defects parallel to the direction of the highest load (horizontally built specimens and components).

Acknowledgements The authors thank the German Research Foundation (Deutsche Forschungsgemeinschaft, DFG) for its financial support within the research project "Microstructure and defect controlled additive manufacturing of gamma titanium aluminides for function-based control of local materials properties" (project number: 404665753). Furthermore, the authors thank the German Research Foundation for funding the "servohydraulic fatigue testing system $250 \mathrm{kN}$ " (INST 212/325-1 FUGG) at TU Dortmund University.

Funding Open Access funding enabled and organized by Projekt DEAL.

\section{Declarations}

Conflict of interest On behalf of all authors, the corresponding author states that there is no conflict of interest.

Open Access This article is licensed under a Creative Commons Attribution 4.0 International License, which permits use, sharing, adaptation, distribution and reproduction in any medium or format, as long as you give appropriate credit to the original author(s) and the source, provide a link to the Creative Commons licence, and indicate if changes were made. The images or other third party material in this article are included in the article's Creative Commons licence, unless indicated otherwise in a credit line to the material. If material is not included in the article's Creative Commons licence and your intended use is not permitted by statutory regulation or exceeds the permitted use, you will need to obtain permission directly from the copyright holder. To view a copy of this licence, visit http://creativecommons.org/licenses/by/4.0/.

\section{References}

1. Kim Y-W (1989) Intermetallic alloys based on gamma titanium aluminide. JOM 41:24-30. https://doi.org/10.1007/BF03220267

2. Clemens H, Smarsly W (2011) Light-weight intermetallic titanium aluminides - status of research and development. Adv Mater Res 278:551-556. https://doi.org/10.4028/www.scientific.net/AMR. 278.551

3. Ma Y, Cuiuri D, Hoye $\mathrm{N}$ et al (2015) The effect of location on the microstructure and mechanical properties of titanium aluminides produced by additive layer manufacturing using in-situ alloying and gas tungsten arc welding. Mater Sci Eng A 631:230-240. https://doi.org/10.1016/j.msea.2015.02.051

4. Tetsui T (2001) Application of TiAl in a turbocharger for passenger vehicles. Adv Eng Mater 3:307-310. https://doi.org/10.1002/ 1527-2648(200105)3:5\%3c307:AID-ADEM307\%3e3.0.CO;2-3

5. Kim Y-W, Kim S-L (2018) Advances in gammalloy materials-processes-application technology: successes, dilemmas, and future. JOM 70:553-560. https://doi.org/10.1007/s11837-018-2747-x

6. Wu X (2006) Review of alloy and process development of TiAl alloys. Intermetallics 14:1114-1122. https://doi.org/10.1016/j. intermet.2005.10.019

7. Appel F, Paul JDH, Oehring M (2011) Gamma titanium aluminide alloys: science and technology. Wiley-VCH Verlag GmbH \& Co. KGaA, Weinheim

8. Bewlay BP, Weimer M, Kelly T et al (2013) The science, technology, and implementation of TiAl alloys in commercial aircraft engines. MRS Proc 1516:49-58. https://doi.org/10.1557/opl.2013. 44

9. Bewlay BP, Nag S, Suzuki A et al (2016) TiAl alloys in commercial aircraft engines. Mater High Temp 33:549-559. https://doi. org/10.1080/09603409.2016.1183068

10. Yang L, Hsu K, Baughman B et al (2017) Additive Manufacturing of metals: the technology, materials, design and production. Springer Series in Advanced Manufacturing. Springer International Publishing, Cham

11. Körner C (2016) Additive manufacturing of metallic components by selective electron beam melting - a review. Int Mater Rev 61:361-377. https://doi.org/10.1080/09506608.2016.1176289

12. Mayer S, Schimbäck D, Wartbichler R et al (2019) Metallography of intermetallic Titanium Aluminides-the (Additive) Manufacturing makes the difference. Practical Metallography 56:567-584. https://doi.org/10.3139/147.110622

13. Wartbichler R, Clemens H, Mayer S (2019) Electron beam melting of a $\beta$-solidifying intermetallic titanium aluminide alloy. Adv Eng Mater 21:1900800. https://doi.org/10.1002/adem.201900800

14. Huang S-C, Hall EL (1991) Plastic deformation and fracture of binary TiAl-base alloys. Metall Trans A 22:427-439. https://doi. org/10.1007/BF02656810

15. Huang S-C, Hall EL (1991) The effects of Cr additions to binary TiAl-base alloys. Metall Mat Trans A 22:2619-2627. https://doi. org/10.1007/BF02851355

16. Clemens H, Wallgram W, Kremmer S et al (2008) Design of novel $\beta$-solidifying TiAl alloys with adjustable $\beta / \mathrm{B} 2$-phase fraction and excellent hot-workability. Adv Eng Mater 10:707-713. https://doi. org/10.1002/adem.200800164

17. Habel U, Heutling F, Kunze $C$ et al. (2016) Forged intermetallic $\gamma$-TiAl based alloy low pressure turbine blade in the geared turbofan. In: Venkatesh V, Pilchak AL, Allison JE et al. (eds) 
2015 World Conference on Titanium, 1. Aufl. Wiley-TMS, s.l., pp 1223-1227

18. Schwaighofer E, Clemens H, Mayer S et al (2014) Microstructural design and mechanical properties of a cast and heat-treated intermetallic multi-phase $\gamma$-TiAl based alloy. Intermetallics 44:128140. https://doi.org/10.1016/j.intermet.2013.09.010

19. Clemens H, Mayer S (2013) Design, processing, microstructure, properties, and applications of advanced intermetallic TiAl alloys. Adv Mater Res 15:191-215. https://doi.org/10.1002/adem.20120 0231

20. Wimler D, Lindemann J, Reith M et al (2021) Designing advanced intermetallic titanium aluminide alloys for additive manufacturing. Intermetallics 131:107109. https://doi.org/10.1016/j.intermet. 2021.107109

21. Reith M, Franke M, Schloffer M et al (2020) Processing 4th generation titanium aluminides via electron beam based additive manufacturing - characterization of microstructure and mechanical properties. Materialia 14:100902. https://doi.org/10.1016/j.mtla. 2020.100902

22. Cormier D, Harrysson O, Mahale T et al (2007) Freeform fabrication of titanium aluminide via electron beam melting using prealloyed and blended powders. Res Lett Mater Sci 2007:1-4. https://doi.org/10.1155/2007/34737

23. Tang HP, Yang GY, Jia WP et al (2015) Additive manufacturing of a high niobium-containing titanium aluminide alloy by selective electron beam melting. Mater Sci Eng A 636:103-107. https://doi. org/10.1016/j.msea.2015.03.079

24. Murr LE, Gaytan SM, Ceylan A et al (2010) Characterization of titanium aluminide alloy components fabricated by additive manufacturing using electron beam melting. Acta Mater 58:1887-1894. https://doi.org/10.1016/j.actamat.2009.11.032

25. Chen Y, Yue H, Wang X (2018) Microstructure, texture and tensile property as a function of scanning speed of Ti-47Al-2Cr- $2 \mathrm{Nb}$ alloy fabricated by selective electron beam melting. Mater Sci Eng A 713:195-205. https://doi.org/10.1016/j.msea.2017.12.020

26. Zhou J, Li H, Yu Y et al (2019) Research on aluminum component change and phase transformation of TiAl-based alloy in electron beam selective melting process under multiple scan. Intermetallics 113:106575. https://doi.org/10.1016/j.intermet.2019.106575

27. Biamino S, Penna A, Ackelid U et al (2011) Electron beam melting of $\mathrm{Ti}-48 \mathrm{Al}-2 \mathrm{Cr}-2 \mathrm{Nb}$ alloy: microstructure and mechanical properties investigation. Intermetallics 19:776-781. https://doi. org/10.1016/j.intermet.2010.11.017

28. Schwerdtfeger J, Körner C (2014) Selective electron beam melting of Ti-48Al-2Nb-2Cr: Microstructure and aluminium loss. Intermetallics 49:29-35. https://doi.org/10.1016/j.intermet.2014. 01.004

29. Todai M, Nakano T, Liu T et al (2017) Effect of building direction on the microstructure and tensile properties of Ti-48Al-2Cr-2Nb alloy additively manufactured by electron beam melting. Addit Manuf 13:61-70. https://doi.org/10.1016/j.addma.2016.11.001

30. Klassen A, Forster VE, Juechter V et al (2017) Numerical simulation of multi-component evaporation during selective electron beam melting of TiAl. J Mater Process Technol 247:280-288. https://doi.org/10.1016/j.jmatprotec.2017.04.016

31. Wartbichler R, Bürstmayr R, Clemens H et al (2019) Selected methods of quantitative phase analysis of an additively manufactured TNM Titanium Aluminide alloy. Pract Metallogr 56:220229. https://doi.org/10.3139/147.110574

32. NarayanaLi PLC-L, Kim S-W et al (2019) High strength and ductility of electron beam melted $\beta$ stabilized $\gamma$-TiAl alloy at $800{ }^{\circ} \mathrm{C}$. Mater Sci Eng A 756:41-45. https://doi.org/10.1016/j.msea.2019. 03.114

33. Moritz J, Teschke M, Marquardt A et al (2021) Electron beam powder bed fusion of $\gamma$-titanium aluminide: Effect of processing parameters on part density, surface characteristics, and aluminum content. Metals 11:1093. https://doi.org/10.3390/met11071093

34. Awd M, Stern F, Kampmann A et al (2018) Microstructural characterization of the anisotropy and cyclic deformation behavior of selective laser melted AlSi10Mg structures. Metals 8:825. https:// doi.org/10.3390/met8100825

35. Ziółkowski G, Chlebus E, Szymczyk P et al (2014) Application of X-ray CT method for discontinuity and porosity detection in 316L stainless steel parts produced with SLM technology. Arch Civ Mech Eng 14:608-614. https://doi.org/10.1016/j.acme.2014. 02.003

36. Juechter V, Franke MM, Merenda T et al (2018) Additive manufacturing of Ti-45Al-4Nb-C by selective electron beam melting for automotive applications. Addit Manuf 22:118-126. https://doi. org/10.1016/j.addma.2018.05.008

37. Terner M, Biamino S, Epicoco P et al (2012) Electron beam melting of high niobium containing TiAl alloy: feasibility investigation. Steel Res Int 83:943-949. https://doi.org/10.1002/srin.20110 0282

38. Bauereiß A, Scharowsky T, Körner C (2014) Defect generation and propagation mechanism during additive manufacturing by selective beam melting. J Mater Process Technol 214:2522-2528. https://doi.org/10.1016/j.jmatprotec.2014.05.002

39. Rausch AM, Markl M, Körner C (2019) Predictive simulation of process windows for powder bed fusion additive manufacturing: influence of the powder size distribution. Comput Math Appl 78:2351-2359. https://doi.org/10.1016/j.camwa.2018.06.029

40. Kim Y-W (1995) Effects of microstructure on the deformation and fracture of $\gamma$-TiAl alloys. Mater Sci Eng A 192-193:519-533. https://doi.org/10.1016/0921-5093(94)03271-8

41. Leitner T, Schloffer M, Mayer S et al (2014) Fracture and R-curve behavior of an intermetallic $\beta$-stabilized TiAl alloy with different nearly lamellar microstructures. Intermetallics 53:1-9. https://doi. org/10.1016/j.intermet.2014.04.005

42. Bruno J, Rochman A, Cassar G (2017) Effect of build orientation of electron beam melting on microstructure and mechanical properties of Ti-6Al-4V. J Mater Eng Perform 26:692-703. https://doi. org/10.1007/s11665-017-2502-4

43. Mohammad A, Alahmari AM, Mohammed MK et al (2017) Effect of energy input on microstructure and mechanical properties of Titanium Aluminide alloy fabricated by the Additive Manufacturing orocess of electron beam melting. Materials (Basel). https:// doi.org/10.3390/ma10020211

44. Tammas-Williams S, Withers PJ, Todd I et al (2016) The effectiveness of hot isostatic pressing for closing porosity in titanium parts manufactured by selective electron beam melting. Metall Mat Trans A 47:1939-1946. https://doi.org/10.1007/ s11661-016-3429-3

45. Seifi M, Salem AA, Satko DP et al (2017) Effects of HIP on microstructural heterogeneity, defect distribution and mechanical properties of additively manufactured EBM Ti-48Al-2Cr-2Nb. J Alloy Compd 729:1118-1135. https://doi.org/10.1016/j.jallcom. 2017.09.163

46. Kastenhuber M, Rashkova B, Clemens H et al (2015) Enhancement of the application temperature of Titanium Aluminides. Berg Huettenmaenn Monatsh 160:342-345. https://doi.org/10.1007/ s00501-015-0378-x

47. Chlupová A, Heczko M, Obrtlík K et al (2020) Effect of heattreatment on the microstructure and fatigue properties of lamellar $\gamma$-TiAl alloyed with Nb, Mo and/or C. Mater Sci Eng A 786:139427. https://doi.org/10.1016/j.msea.2020.139427

Publisher's Note Springer Nature remains neutral with regard to jurisdictional claims in published maps and institutional affiliations. 